\title{
LA SOLIDEZ DE LA ECONOMÍA CHILENA A LA LUZ DE LAS REFORMAS ESTRUCTURALES: 1970-1997
}

\author{
Ángeles Sánchez Díez*
}

\section{INTRODUCCIÓN}

Aunque ensombrecidas por las crisis financieras recientes, en el fin del milenio las economías latinoamericanas parecen haber salido de la profunda crisis que vivieron en la década pasada. Los gobiernos, bajo las directrices de las instituciones internacionales, abogaron por un cambio en la concepción de sus estrategias de desarrollo de forma que emprendieron un conjunto de reformas de carácter estructural que empiezan a tener su reflejo en el devenir económico y social del continente. Entre las economías latinoamericanas destaca el caso chileno por su solidez reflejándose en las cifras macroeconómicas especialmente en el bienio 1996$1997^{\prime}$. De esta forma el producto interior bruto aumentó un $7,4 \%$ en 1996 y un 7,1\% en 1997 . Los porcentajes de inversión sobre el PIB se situaron en el 26,6\% y el 26,9\% en 1996 y 1997 manteniéndose la tendencia creciente de los años anteriores. El control de la inflación sigue descendiendo alcanzando las cifras del 6,6\% y del 6\% en 1996 y 1997 . Por su parte el desempleo era del 6,5\% en 1997 frente al 6,1\% de 1997, aunque hay que señalar que este indicador ha mostrado incrementos en el último bienio. El crecimiento de los salarios ha permitido que la demanda interna no caiga y no se entre en una fase de recesión. El comercio exterior ha seguido aumentando, reflejo de la inserción internacional chilena, sin embargo en los dos últimos años el saldo comercial fue deficitario consecuencia de un mayor dinamismo de las importaciones en lo que ha podido influir la apreciación real del peso $^{2}$. Finalmente se puede resaltar el éxito en las estrategias de inversiones extranjeras directas que llegó a alcanzar en 1997, el monto de 5041 millones de dólares a través del Decreto-Ley 600, centrado básicamente en la minería (32,2\% del total), el comercio, la construcción, el transporte, las comunicaciones $(29,5 \%)$ y la electricidad, gas y agua $(27,7 \%)$.

El hecho de que la economía chilena se presente como una de las más sólidas entre las latinoamericanas deriva de los importantes cambios que durante las pasadas décadas se produjeron. La situación actual de la economía debe ser explicada desde una visión histórica que permita observar cuales fueron las implicaciones de las distintas reformas estructurales que tuvieron lugar entre 1970 y 1995. Sólo de esta forma es posible conocer como fue evolucionando el contexto económico, social y político en el cual, en primer lugar bajo un modelo de carácter socialista, posteriormente bajo la supervisión de un régimen dictatorial de corte monetarista y finalmente bajo los gobiernos de una democracia vigilada, se desarrollaron los cambios económicos e institucionales que han hecho de Chile el país latinoamericano más saneado.

Para el estudio de este largo proceso se propone la siguiente división en períodos en los que se recogen las distintas etapas por las que ha pasado la economía chilena, los regímenes políticos en los que se sustentaban y las principales características teóricas que se pueden suscribir. Con este referente se van a analizar cuales fueron las principales reformas estructurales de cada periodo resaltando los resultados económicos exitosos y aquellos que tuvieron un tinte negativo (1. Gobierno de la Unidad Popular, 2. Gobierno de la Junta Militar, 3. La Transición a la Democracia) para posteriormente observar la evolución de las principales variables de la economía chilena de una forma global entre 1970 y 1997 (4.Balance de los cambios estructurales). Finalizando con unas breves lecciones relativas al periodo analizado de la historia económica chilena.

\section{EL GOBIERNO DE LA UNIDAD POPULAR: 1970-1973}

La Unidad Popular, una coalición de partidos de izquierdas, articuló a través de la denominada "vía chilena hacia el socialismo", las transformaciones que, a su juicio, necesitaba Chile para liberarse de la dependencia que sufría de las naciones desarrolladas, especialmente de los EEUU. Constituía una experiencia única que aunque había sido adelantada por los clásicos del marxismo nunca se había

Economista, cursa el Programa de Doctorado "Integración y Desarrollo Económico” de la Universidad Autónoma de Madrid. Este artí culo es una síntesis de la memoria de licenciatura dirigida por el profesor titular José Manuel García de la Cruz.

1. Los datos proceden de las Memorias del Banco Central de Chile.

2. El índice que registra la evolución del tipo de cambio real con base 100 en 1986 pasó del 96,9 en 1993, a 94,3 en 1994, a 88,9 a 1995, a 84,7 en 1996 y a 78,3 en 1997. 


\begin{tabular}{|c|c|c|}
\hline \multicolumn{3}{|c|}{ REFORMAS ESTRUCTURALES Y DESARROLLO EN CHILE. 1975-1995 } \\
\hline \multicolumn{2}{|c|}{ Periodo } & \begin{tabular}{|c|} 
Elementos \\
\end{tabular} \\
\hline \multicolumn{2}{|c|}{$\begin{array}{l}\text { Gobierno de la Unidad Popular: } \\
\text { 1970-1973 }\end{array}$} & $\begin{array}{l}\text { Via Chilena hacia el Socialismo: estructuralismo. } \\
\text { Presencia del Estado como agente principal. } \\
\text { Respeto a la legalidad constituida. } \\
\text { Economia de Plan. }\end{array}$ \\
\hline \multirow[t]{2}{*}{$\begin{array}{l}\text { Mandato de la } \\
\text { Junta Militar: } \\
\text { 1974-1989 }\end{array}$} & $\begin{array}{l}1^{3} \text { etapa: } \\
1974-1982\end{array}$ & $\begin{array}{l}\text { - Monetarismo ortodoxo: monetarismo de la Escuela } \\
\text { de Chicago } \\
\text { - Monetarismo de Economia Cerrada } \\
\text { - Monetarismo de Transición } \\
\text { Liberalización y desregulación de los mercados. } \\
\text { Minimización de las funciones del Estado y exaltación } \\
\text { del Sector Privado. } \\
\text { Libre mercado. }\end{array}$ \\
\hline & $\begin{array}{l}2^{3} \text { etapa: } \\
\text { 1983-1989 }\end{array}$ & - Correcciones del monetarismo: neoliberalismo. \\
\hline \multicolumn{2}{|c|}{$\begin{array}{l}\text { Transición a la Democracia: } \\
1990-1995^{3}\end{array}$} & $\begin{array}{l}\text { - Transformación Productiva con Equidad: } \\
\text { neoestructuralismo. }\end{array}$ \\
\hline \multicolumn{3}{|c|}{ Fuente: Elaboración propia. } \\
\hline
\end{tabular}

materializado. El proceso suponía la construcción de una sociedad socialista después de una transición basada en el respeto de las instituciones y la legalidad existente.

El Programa contemplaba distintos ejes entre el que se encontraba la "Nueva Economía" cuyos objetivos principales eran la reorientación de la capacidad productiva, garantizar un puesto de trabajo a todos los ciudadanos en edad de trabajar, la liberalización de la subordinación del capital extranjero, crecimiento rápido y descentralizado, en materia de comercio exterior: aumento y diversificación de las exportaciones, nuevos mercados e independencia financiera y tecnológica y, finalmente garantizar la estabilidad monetaria. Para alcanzar estas metas se articularon distintas reformas de carácter estructural entre las que destacaron la creación del Área de Propiedad Social, la profundización de la Reforma Agraria y la nacionalización de la Gran Minería.

La creación del Área de Propiedad Social (APS) no suponía la desaparición de la propiedad privada que juntas convivirían con el área de propiedad mixta. Incluía a todas las empresas del Estado más las que fueran expropiadas. El Programa establecía que podían ser susceptibles de nacionalización empresas, de la Gran Minería, del Sistema Financiero, de Comercio Exterior, las Grandes Empresa y los Monopolios y en general todas aquellas que condicionaran el desarrollo económico y social.

La Reforma Agraria se había iniciado con el gobierno de E. Frei en 1965, sin embargo, el nuevo gobierno la consideraba insuficiente y articuló una profundización de ésta. Era un proceso simultaneo y complementario respecto a las transformaciones generales. Las directrices en la implementación de la Reforma Agraria fueron: La expropiación de los predios que superaran un determinado tamaño (como media 80 hectáreas), la incorporación inmediata al cultivo de las tierras estatales, la organización en cooperativas, la asignación de tierras a pequeños agricultores, la reorganización de la propiedad minifundaria y el respeto a las comunidades indígenas. La Reforma Agraria se realizó dentro del marco de la Ley Agraria heredada del gobierno demócrata-cristiano y se crearon los Centros de Reforma Agraria (CERAS) desde donde se gestionaban los cambios que la profundización exigía. Así entre el 4 de noviembre de 1970 y el 22 de marzo de 1973 se expropiaron 3.628 predios que suponían 5.585 .327 hectáreas y 33.948 familias frente a los 1.408 predios, 3.564 .553 hectáreas y 20.976 familias expropiadas entre 1965 y el 4 de septiembre de 1970 .
La nacionalización de la Gran Minería aparecía como un objetivo expreso del Programa en el que se establecía que este sector debería pasar a formar parte del Área de Propiedad Social. Se apoyaba en la Declaración 1803 (XVII) de Naciones Unidas que reconoce "el derecho inalienable de todo Estado a disponer libremente de sus riqueza y recursos naturales en conformidad con sus intereses nacionales". El gobierno de E. Frei (1964-1970) había articulado la denominada "chilenización" por la que se había hecho con parte de las compañías mineras ${ }^{4}$ más importantes. Sin embargo, a juicio del gobierno popular y al igual que la Reforma Agraria, ésta era una medida insuficiente y erróneamente gestionada.

La vía chilena hacia el socialismo contaba con importantes debilidades tales como: La ausencia de control de los canales de distribución que afectó a la producción, la comercialización y el consumo ${ }^{5}$, los problemas internos de organización derivados de las luchas internas entre los partidos Socialista y Comunista, la infravaloración de los riesgos que el modelo suponía y del verdadero poder del movimiento opositor y finalmente, se puede mencionar la necesidad de que las reformas se acometieran de una manera decidida de forma que no dieran lugar a situaciones de dualidad.

La vía chilena hacia el socialismo terminó de una manera violenta convirtiéndose en una tragedia que se prolongó por 17 años. Se pueden hacer distintas interpretaciones del fracaso de dicho modelo. La interpretación tradicional resalta la importancia del boicot parlamentario que imposibilitó que se acometieran los cambios necesarios que hubieran permitido una transición óptima hacia el socialismo. Sin embargo, existen otros análisis alternativos que resaltan los factores internos y los factores externos del modelo. El primero hace referencia a la existencia de una contradicción de base en la propia concepción de la vía chilena en tanto que se concebía la transición de una economía capitalista dependiente a una sociedad socialista valiéndose de las instituciones burguesas, se observa una confrontación de intereses entre el fin (sociedad socialista) y los mecanismos (instituciones burguesas). El segundo análisis se centra en las presiones externas de forma que independientemente de los errores o aciertos de la implantación de la transición chilena, los intereses de las multinacionales, especialmente americanas, no hubieran permitido bajo ningún supuesto el triunfo de la vía chilena hacia el socialismo.

3. La transición a la democracia se ha considerado de cinco años, incluyen el primer gobierno democrático (P. Aylwin) en su totalidad y los primeros meses del gobierno de Frei con el fin de observar que el proceso de transición estaba consolidado de forma que era posible afrontar unas elecciones y posteriormente realizar el traspaso de poderes de un gobierno a otro, sin que la democracia peligrara.

4. A través de los Convenios del Cobre el estado se hizo con el $51 \%$ de las acciones del Teniente y el $25 \%$ de las demás compañías.

5. A partir de 1972 empezó a formarse el mercado negro de mercancías - productos básicos como la leche, los productos de cuidado infantil, la carne, etc.- derivado de problemas de distribución -sector no nacionalizado-de dichos bienes y, no por una situación de escasez ocasionada por problemas en la producción. Estos productos fueron retenidos por los grupos ligados a la oposición más dura a la Unidad Popular provocando una situación de escasez en el mercado legal que se intentó subsanar, en parte, con medidas de racionamiento. 


\section{GOBIERNO DE LA UNIDAD POPULAR. 1970-1973}

\begin{tabular}{|c|c|}
\hline \multicolumn{2}{|c|}{ GOBIERNO DE LA UNIDAD POPULAR. 1970-1973 } \\
\hline RESULTADOS EXITOSOS & \begin{tabular}{|l} 
RESULTADOS NEGATIVOS \\
\end{tabular} \\
\hline $\begin{array}{l}\text { - } \\
\text { - } \text { Aumento del PIB * } \\
\text { - Aumento de la producción minera. } \\
\text { - } \text { Aumento de la producción } \\
\text { manufacturada. } \\
\text { - Cumplimiento de las expectativas de } \\
\text { expropiaciones agrarias. } \\
\text { - Mercado de trabajo. } \\
\text { - Mejora del poder adquisitivo: via } \\
\text { salarios y servicios públicos. }\end{array}$ & $\begin{array}{l}\text { - Permitir los elementos que ocasionaron la } \\
\text { formación del mercado negro y el } \\
\text { desabastecimiento. } \\
\text { - Diminución de la formación bruta de } \\
\text { capital fijo. } \\
\text { - Problemas en los suministros. } \\
\text { - Aumento del déficit fiscal. } \\
\text { - Aumento del déficit comercial. }\end{array}$ \\
\hline
\end{tabular}

En la siguiente tabla se resumen cuales fueron los principales éxitos así como los principales resultados negativos en materia económica del gobierno de la Unidad Popular:

\section{EL GOBIERNO DE LA JUNTA MILITAR: 1973-1989}

El periodo de la Junta Militar desde el punto de vista de la gestión económica se dividió en dos etapas: desde 1973 a 1982, el monetarismo ortodoxo inspirado por la llamada Escuela de Chicago y a partir de 1983 cuando se introdujeron ciertas correcciones aunque siempre manteniendo los principios del modelo neoliberal. A su vez el monetarismo ortodoxo pasó por distintas fases en las que se apreciaron diferencias en la concepción de los equilibrios de las variables macroeconómicas siendo el eje central los mecanismos de control de la inflación. De esta forma se distingue: El monetarismo de economía cerrada -1974/1976- (los precios se consideraban una variable endógena), la fase de transición o de desindexación de precios -1976/1979- (se introducen las expectativas racionales) y el monetarismo de economía abierta o de balanza de pagos -1979/1982- (los precios es una variable exógena).

Los pilares del monetarismo eran la liberalización y desregulación de los mercados con el objetivo de modernizar el país en un contexto de economía capitalista. Siempre hubo una correlación muy próxima entre los postulados teóricos y la implantación práctica hasta que la crisis productiva y financiera de 1982 obligó a los gestores de la política económica a abandonar la rigidez del modelo introduciéndose distintas correcciones que lo flexibilizan. El caso chileno constituyó uno de los ejemplos más radicales del pensamiento monetarista que se apoyó principalmente en una férrea dictadura militar que eliminó toda posibilidad de disidencia manifestada públicamente. En este contexto se desarrollan las privatizaciones, la apertura comercial, la liberalización financiera y las siete modernizaciones.

Las privatizaciones se correspondían con el principio de desmantelamiento del sector público reforzando el papel del sector privado. La $1^{a}$ ronda, entre 1974 y 1979 , tuvo por objeto devolver a los antiguos dueños las propiedades expropiadas por el gobierno de la Unidad Popular. Sin embargo, la falta de transparencia con la que se llevó a cabo el proceso permitió la acumulación de la riqueza en pocas manos creándose los denominados "grupos" financieroproductivos que jugarían un papel fundamental en la crisis del modelo ortodoxo en 1982. Estos conglomerados financiero-productivos agrupaban a grandes bancos comerciales y actividades industriales en unas mismas manos.

La reforma comercial comenzó con la arancelización de todas las barreras no arancelarias para posteriormente ir reduciendo las tarifas hasta el $10 \%$, la retirada del Pacto Andino, aludiendo a la Decisión 24 referida a inversiones extranjeras la cual coartaba las posibilidades de desarrollo nacionales y una política de mini-devaluaciones de 1974 a 1979 , hasta determinar una tipo de cambio nominal fijo. Sin embargo, el tipo de cambio real, especialmente a partir de 1979, observó una importante apreciación real. La combinación de la reducción arancelaria (fomenta las importaciones) y el mantenimiento de un tipo de cambio apreciado (disminuye la competitividad de las exportaciones) fue dando lugar a un crecimiento acelerado del déficit comercial en el marco de una economía que se abría, alcanzando la magnitud en 1981 de 762 billones de pesos constantes de 1987

La reforma financiera atendía al pilar básico de liberalización y desregulación. Dentro de la filosofía general del modelo, dicha reforma quedaba plenamente justificada ya que el sector se encontraba altamente intervenido en el periodo anterior. Todas las medidas fueron encaminadas a establecer la libre competencia entre las entidades financieras e insertar al mercado de capitales chileno en los mercados internacionales. De esta forma y favorecido por el proceso de privatizaciones y la falta de transparencia con la que se realizó, se crearon y posteriormente se fueron consolidación de los denominados "grupos". En el periodo 1974-1982, 2823 empresas quebraron sin producirse un proceso de reestructuración ya que los recursos liberados durante el periodo no se ocuparon en actividades productivas de mayor productividad que hubieran tenido su reflejo en el saldo neto exterior y en el empleo.

Finalmente las "siete modernizaciones" se centraron en el mercado de trabajo, el sistema de Seguridad Social, la agricultura, la sanidad, la educación, la justicia y la administración. El objetivo perseguido era extender la descentralización y desestatitación a dichos campos en pro del libre funcionamiento de los mercados. La Ley del Trabajo, entre otras medidas, legalizó el derecho de la huelga bajo unas condiciones muy peculiares -era posible contratar a trabajadores suplentes y el límite se fijaba en 60 días- que desvirtuaban el propio concepto de huelga. La privatización de la Seguridad Social consiguió un nivel de cobertura escaso (en 1989 la población cubierta por la previsión privada era del $41 \%$ de la población activa) mientras que paralelamente se fue reduciendo la cobertura pública $(7,4 \%$ en 1989$)$. La reforma de la Ley Agraria vino a legitimar la marcha atrás en las expropiaciones llevadas a cabo por la Democracia Cristina y la Unidad Popular facilitando la acumulación de la tierra en manos de una minoría. Importantes también fueron las reformas de la sanidad y la educación que dieron lugar a una situación dual con grandes diferencias entre la calidad de la provisión pública y privada.

Todos estos elementos combinados, unidos al estallido de la crisis general de América Latina terminaron con la concepción más ortodoxa del modelo monetarista, además el rechazo de los instrumentos de política activa le hicieron ser especialmente vulnerable a la crisis ya mencionada. El 
fatídico año de 1982 se cerró con caídas del 14,1\% en el PIB, del $21 \%$ en el producto manufacturero, una tasa de paro del $19,6 \%$, entre otros desequilibrios.

Se hizo necesario abandonar la rigidez del modelo y se introdujeron distintas medidas correctoras. En un primer momento se consideró la crisis como coyuntural introduciéndose diferentes tipos de cambio, un programa de dinamización del sector productivo y nacionalizándose una parte del sector bancario que pasó a formar parte de la denominada "área rara". En 1985 se introducen medidas correctoras de carácter estructural destacando en política macroeconómica; se pasa del ajuste automático al manejo de políticas activas de forma que se orienta el gasto fiscal hacia la inversión, se aumenta el tipo de interés y se devalúa la moneda, en referencia a las reformas estructurales; se acomete la $2^{a}$ Ronda de Privatizaciones (1985/1989) afectando a las empresas del "área rara" y las tradicionales del Estado, se rompe con el tipo de cambio fijo, se introducen incentivos a las exportaciones y aumentos en los aranceles (hasta el 35\%), se reforman los mercados de valores y se crean instrumentos de conversión de la deuda con el fin de reducirla a través del Compendio del Banco Central.

En las siguientes tablas se pueden apreciar los resultados positivos y negativos del gobierno militar, resultado de la gestión del modelo monetarista ortodoxo (1974-1982) y de la corrección de este dentro de los postulados neoliberales (1983-1989).

\begin{tabular}{|c|c|}
\hline \multicolumn{2}{|r|}{ GOBIERNO DE LA JUNTA MILITAR 1974/1989 } \\
\hline \multicolumn{2}{|r|}{ RESULTADOS EXITOSOS } \\
\hline $\begin{array}{l}I^{\text {a }} \text { etapa: } \\
\text { 1974-1982 }\end{array}$ & $\begin{array}{l}\text { - Aumento del PIB. } \\
\text { - Aumento en la producción minera. } \\
\text { - Disminución del déficit fiscal. } \\
\text { - Expansión comercial. } \\
\text { - Disminución de los costes de las importaciones. } \\
\text { - Diversificación de las exportaciones. }\end{array}$ \\
\hline $\begin{array}{l}2^{3} \text { etapa: } \\
1983-1989\end{array}$ & $\begin{array}{l}\text { - Estabilización macroeconómica. } \\
\text { - } \text { Credibilidad de la política cambiaria. } \\
\text { - Aceleración del crecimiento del PIB. } \\
\text { - } \text { Aumento en la producción minera. } \\
\text { - Reducción de la inflación. } \\
\text { - Reconstrucción de la capacidad productiva y el sistema financiero. } \\
\text { - Reducción de la deuda. } \\
\text { - Mejoras en la competitividad internacional. }\end{array}$ \\
\hline
\end{tabular}

\begin{tabular}{|c|c|}
\hline \multicolumn{2}{|r|}{ RESULTADOS ECONÓMICOS DE LA JUNTA MILITAR 1974/1989 } \\
\hline \multicolumn{2}{|c|}{ RESULTADOS NEGATIVOS } \\
\hline $\begin{array}{l}1^{a} \text { etapa: } \\
1974-1982\end{array}$ & $\begin{array}{l}\text { - Falta de transparencia en las privatizaciones, permitiendo la } \\
\text { formación de los grupos. } \\
\text { - Brote inflacionista. Retraso en la disminución de la inflación } \\
\text { respecto a las expectativas. } \\
\text { - Crisis de } 1975 \text {. } \\
\text { - } \text { - Destrucción de la capacidad productiva manufacturera. } \\
\text { - Desestabilización del mercado laboral. } \\
\text { - } \text { - Exisis productiva y financiera de 1982. Reorientación del modelo. } \\
\text { - Expansión del déficit comercial. } \\
\text { - Formación de un circulo vicioso endeudamiento privado-consumo. } \\
\text { - Fomento de la dualidad. Ausencia del Estado de Bienestar. } \\
\text { Fragmentación y desestructuración social. }\end{array}$ \\
\hline $\begin{array}{l}2^{a} \text { etapa: } \\
\text { 1983-1989 }\end{array}$ & $\begin{array}{l}\text { - Consolidación de un círculo vicioso endeudamiento privado- } \\
\text { consumo. } \\
\text { - Mantenimiento de la dualidad. Ausencia del Estado de Bienestar. } \\
\text { - Desestructuración social. }\end{array}$ \\
\hline Fuente: Ela & ción propia \\
\hline
\end{tabular}

\section{LA TRANSICIÓN A LA DEMOCRACIA: 1990-1995}

Derivado de la propia Constitución de 1980, en 1988 tiene lugar el plebiscito en el que se debía ratificar que el general Augusto Pinochet siguiera al mando de la República, el triunfo del NO desencadena los pasos necesarios para que Chile recuperara su democracia. De esta forma en 1989 la Concertación ${ }^{6}$ gana las elecciones presidencial y Patricio Aylwin toma el poder en 1990. Considerando la última propuesta de la CEPAL de principios de la década las economías han de perseguir la estabilidad macroeconómica, la apertura comercial y la denominada Transformación Productiva con Equidad. En este marco el gran reto para Chile en el siglo XXI lo constituye "generar crecimiento económico acompañado de equidad" difundiendo productividad a través de la sociedad e insertando en la economía el mayor número de personas con la mayor capacidad para producir. Los grandes retos para la sociedad chilena lo constituyen a nivel económico; la consolidación de un desarrollo exportador industrializante, a nivel político; corregir las anomalías heredadas de la Constitución de 1980 así como las pactadas en los primeros años de la transición y, a nivel social; alcanzar los denominados equilibrios "macrosociales". En este contexto se abre el debate del papel del Estado de forma que se sitúe entre el intervencionista de la Unidad Popular y el pasivo de la Junta Militar. Se puede afirmar que la propuesta para la transición democrática era: "impulsar un desarrollo exportador industrializante mediante políticas destinadas a aumentar la proporción de las exportaciones de un mayor dinamismo en el comercio internacional, y a eslabonar otras ramas productivas y estratos empresariales internos a la expansión del sector exportador" (Sunkel, 1992).

A continuación se resumen los datos económicos del periodo 1990/1995.

\begin{tabular}{|c|c|}
\hline \multicolumn{2}{|c|}{ TRANSICIÓN A LA DEMOCRACIA 1990-1995 } \\
\hline RESULTADOS EXITOSOS & \begin{tabular}{|l} 
RESULTADOS NEGATIVOS \\
\end{tabular} \\
\hline $\begin{array}{l}\text { - Altas tasas de crecimiento del PIB. } \\
\text { - Reducción de la inflación. } \\
\text { - Mejoras en la competitividad } \\
\text { internacional. } \\
\text { - Mercado de trabajo. } \\
\text { - Aceleración en el proceso de } \\
\text { internacionalización de la economia. } \\
\text { - Superávit comercial. } \\
\text { - Expansión de la inversión extranjera } \\
\text { directa. }\end{array}$ & $\begin{array}{l}\text { - Expansión del déficit fiscal. } \\
\text { - Crecimiento de la deuda externa. } \\
\text { - } \text { endeudamimiento de un circulo vicioso } \\
\text { privado-consumo. }\end{array}$ \\
\hline Fuente: Elaboración Propia & \\
\hline
\end{tabular}

Quedan, sin embargo, grandes retos que constituyen los desafíos del siglo XXI, entre los que se pueden destacar: la introducción de elementos de equidad, la eliminación de la pobreza, el desarrollo industrializante con una base productiva sólida con vinculaciones en la totalidad del tejido productivo nacional e internacional, la cualificación de los recursos humanos, la diversificación de las exportaciones, la disminución del endeudamiento externo y la inserción en los esquemas de integración con el fin de mantener el

6. Surge como un movimiento de oposición al General A. Pinochet. Los principales partidos son la Democracia Cristiana y el Partido Socialista. 
crecimiento basado en las exportaciones, introducir políticas de cohesión social, incrementar el poder de negociación internacional, etc.

\section{BALANCE DE LOS CAMBIOS ESTRUCTURALES}

Un análisis conjunto de las variables económicas más importantes permiten observar las repercusiones de las distintas medidas de política económica sobre la realidad chilena así como analizar cuales fueron las diferencias más significativas y las prioridades en cada periodo.

\section{TASA DE CRECIMIENTO DEL PIB}

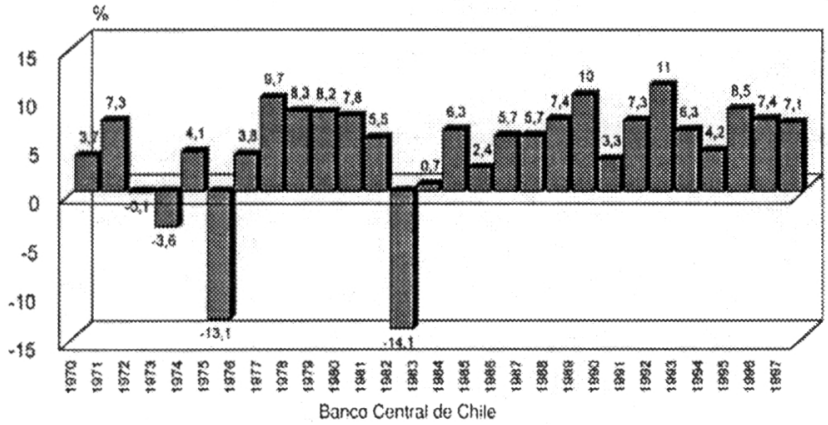

Resaltan las caídas del PIB en 1975, producto del Plan de Estabilización, y en 1982 reflejo de la crisis del modelo monetarista. Resulta por lo tanto significativo que las dos grandes crisis se produjeran durante el periodo de gestión monetarista. Además, el denominado "milagro chileno" entre 1979 y 1982 esconde una importante desaceleración en el crecimiento económico siendo las cifras similares a las de 1971 (único año plenamente válido para el análisis de la U.P), así como a los de distintos años del fin de la dictadura militar y de la democracia. Por lo tanto dicho milagro no a de ser considerado como tal sin más consideraciones, ya que durante estos años se fueron acumulando distintos elementos con sesgos antiindustriales y de desestabilización financiera que ocasionarían la crisis definitiva del modelo.

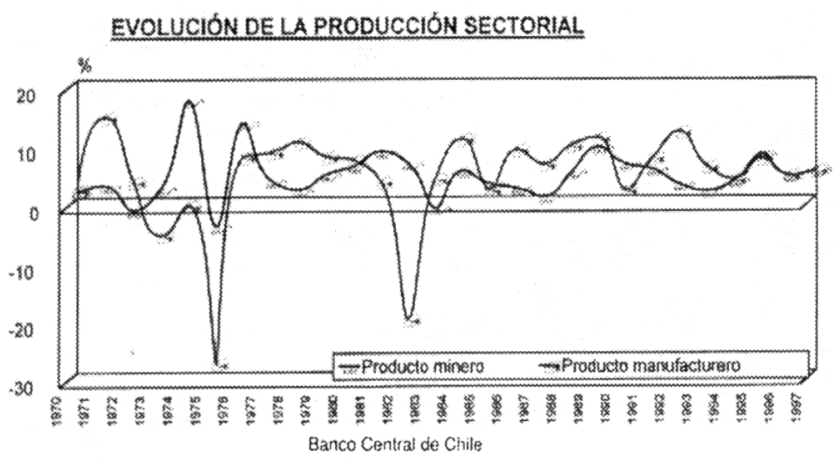

El crecimiento económico tuvo lugar en tiempos de la Unidad Popular sin el apoyo de la minería que contó con numerosos problemas, sin embargo, las inversiones realizadas durante la "chilenización" de Frei y con la nacionalización de la Gran Minería, unido al fin de la desestabilización en dicho sector y a la subida en el precio del cobre permitió un importante aumento en 1974. La minería siguió los ciclos de la economía aunque no viéndose tan afectado por las respectivas crisis que se centraron en las manufacturas.

La evolución de la tasa de crecimiento del producto industrial muestra claramente cual fue el sector perjudicado por las crisis de 1975 y 1982, así como las repercusiones de la desestabilización de 1973. La política popular apostaba por el desarrollo industrial dentro de la filosofía latinoamericana que consideraba a la industrialización como una condición necesaria, aunque no suficiente, para el desarrollo nacional. La fase del monetarismo de balanza de pagos pone de manifiesto los efectos de las políticas con sesgos antiindustriales que fueron minando con la capacidad productiva de Chile.

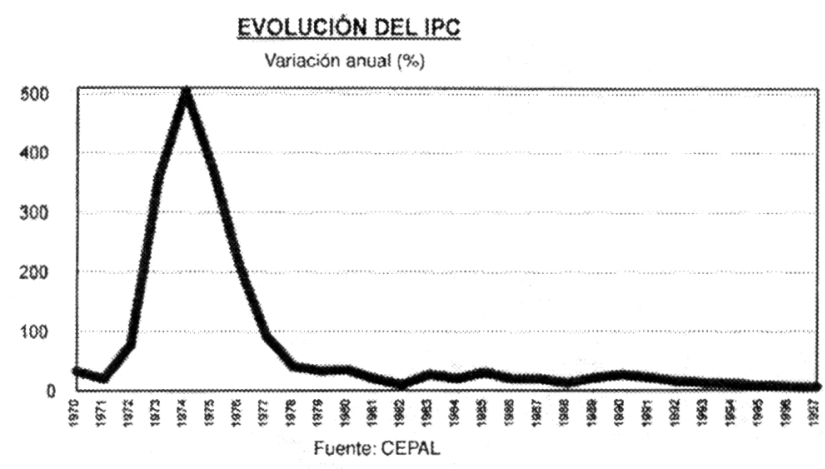

Al margen de las variaciones que se produjeron a partir de 1982, que aunque con múltiples excepciones siempre se observa una tendencia al control del proceso inflacionario, es importante analizar la cresta que tiene lugar entre 1971 y 1979. Los precios comienzan a aumentar en 1972 como consecuencia de la aparición del mercado negro y se disparan en 1973. En este año conviven dos fuentes inflacionarias, hasta el 11 de septiembre se mantiene la existencia del mercado negro y la situación caótica generada por el proceso de desestabilización y, a partir de esta fecha se debe a la brusca eliminación de los precios planificados en un contexto de liberalización y desregulación. La importancia del proceso inflacionario que se derivó del cambio del modelo no es solo importante por las magnitudes registradas, sino también porque el principal objetivo de los gestores de la economía era el control de los precios que, según la propia teoría, se alcanzaría en unos meses de forma automática. Sin embargo, esto no se produjo por lo cual se debieron hacer distintas revisiones teóricas dando lugar a las distintas fases del monetarismo, todas ellas centradas en el análisis de la inflación.

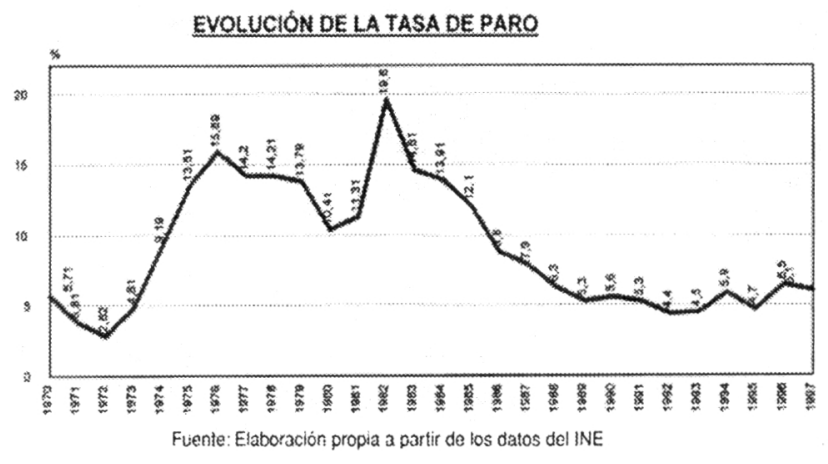


La evolución de la tasa de paro muestra las prioridades de los distintos periodos así como la repercusión de las medidas acometidas por cada gobierno. Se observan las buenas cifras del gobierno popular que identifica con las prioridades establecidas en el Programa de la U.P. El periodo militar comienza con importantes incrementos en la tasa de paro que nunca fueron reconocidos como estructurales. Durante el denominado "milagro económico" la tasa de paro bajo ligeramente aunque es importante señalar que se movió en unos niveles muy altos. El derrumbe del modelo se traduce en el mayor paro registrado conocido en los 27 años estudiados. A partir de este momento y, con contadas excepciones, comienza una senda de decrecimiento de la tasa de paro. Sin embargo, el último bienio se ha caracterizado por ligeros aumentos en el paro registrado.

\section{EVOLUCIÓN DE LOS SALARIOS}

Indices en términos reales

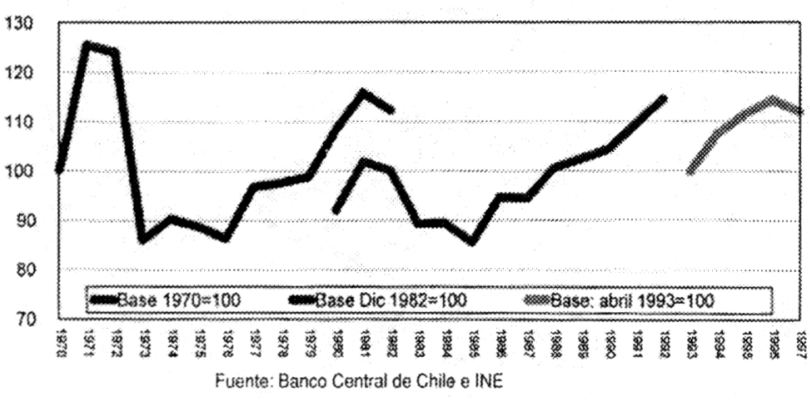

Tras el crecimiento de 1971 y la leve caída de 1972, se produjo una importante caída en las remuneraciones que viene a coincidir con el periodo de desestabilización y el cambio del modelo. Entre 1976 y 1981 se observa el resultado de las políticas de indexación de los salarios que a partir de 1979 respaldadas por la Ley del Trabajo. A pesar del importante crecimiento del periodo monetarista se observa que el valor para 1981 (máximo) no alcanzaba la cifra de 1971 lo cual pone de manifiesto el importante retraso de dicha variable. Este hecho es sumamente importante, máxime si se tiene en cuenta las altas tasas de paro y la ausencia del Estado de Bienestar que gestionara políticas de cohesión social. La recuperación no comienza hasta 1986 aunque una vez más se puede observar que este indicador muestra un importante retardo en su evolución.

\section{EVOLUCIÓN DEL COMERCIO EXTERIOR}

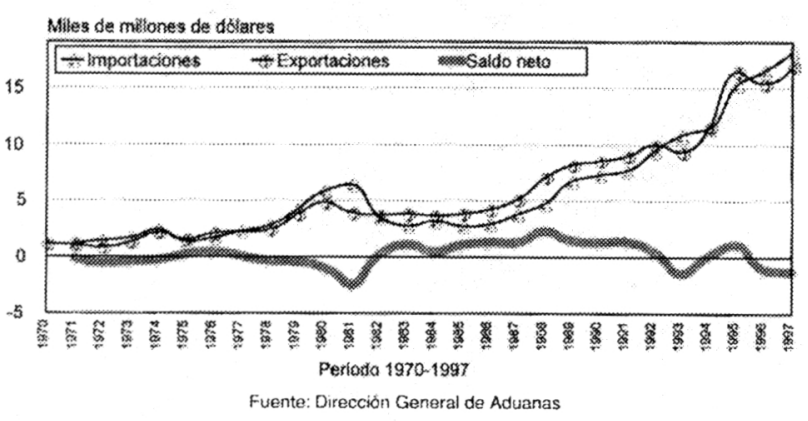

Se pone de manifiesto el proceso de internacionalización de la economía chilena. El monetarismo se inició con un importante déficit en el saldo neto exterior que respondía a la apertura comercial. A partir de 1976 se fueron registrando saldos negativos crecientes reflejo de la gestión de la política comercial que favorecía el incremento de las importaciones por encima del de las exportaciones. Este llegó a su máximo en 1981. Por el contrario en 1982, el saldo neto disminuyó su déficit ocasionado básicamente por la contracción de las importaciones. Tras las correcciones introducidas se registraron situaciones de superávit comercial.

DIVERSIFICACIÓN DE LAS EXPORTACIONES

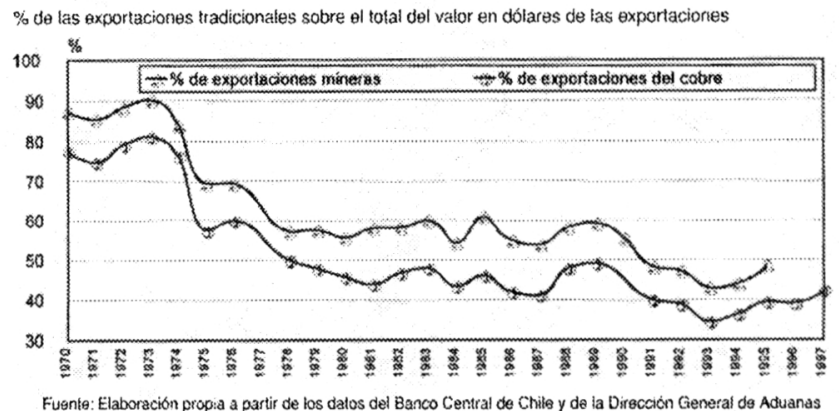

Obsérvese que se carece de los datos del valor de las exportaciones mineras de 1977, 1996 y 1997, así como de los relativos al cobre en 1977 y 1990.

La diversificación de las exportaciones constituyó el principal éxito del periodo militar, pese a que durante la década de los 80 se estacionó fluctuando el peso del valor de las exportaciones mineras entre el $54 \%$ y el $60 \%$. La democracia consiguió vitalizar el proceso de diversificación en sus primeros años aunque a partir de 1994 se ha registrado un retroceso en esta materia por lo que la diversificación de las exportaciones sigue constituyendo uno de los grandes retos del futuro.

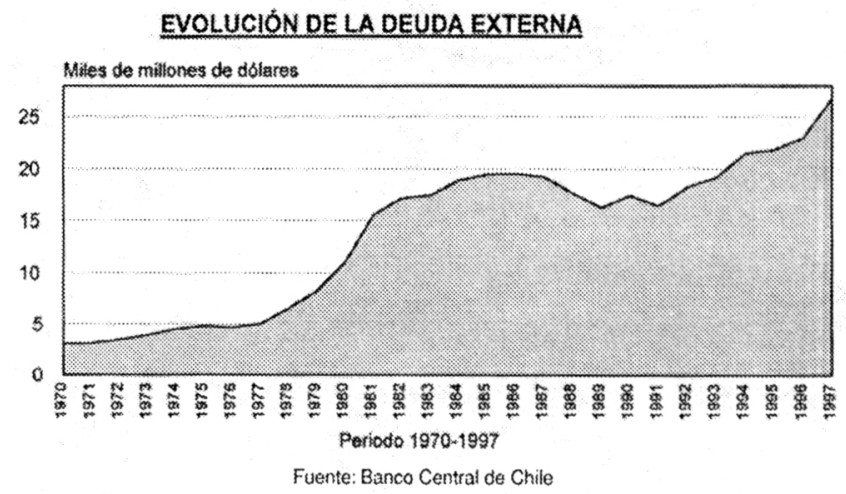

Con la liberalización financiera a partir de 1977 comienza la expansión de la deuda externa que con anterioridad ya suponía un grave problema para la economía chilena. Pese que desde 1982 el crecimiento se desacelera no es hasta 1987 como resultado de los nuevos instrumentos de política cuando esta variable inicia su descenso. Sin embargo, la deuda externa supone uno de los retos de la democracia ya que durante la década de los 90 se registran nuevos incrementos en el endeudamiento externo.

Las diferencias entre la inversión autorizada y la materializada son importantes y difieren según los países y los sectores. Importante es destacar que la inversión extranjera 


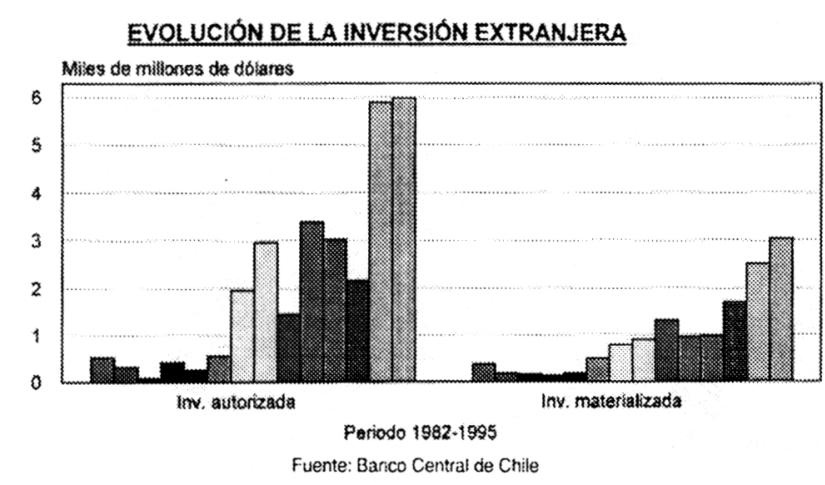

directa constituyó, junto con la expansión de las exportaciones, uno de los pilares de la estrategia de desarrollo de Chile a finales de los años 80 y durante la década de los 90 .

\section{LECCIONES DE LA EXPERIENCIA CHILENA}

La situación económica de un país ha de analizarse desde una perspectiva a largo plazo que permita conocer las estructuras sobre las que se desenvuelven las relaciones de producción, distribución y consumo en el ámbito nacional e internacional, sin olvidar la importancia que el contexto sociopolítico tiene sobre el desenvolvimiento económico.

Podría firmarse que tanto la gestión planificada de la Unidad Popular como la fidelidad a los postulados ortodoxos del monetarismo de la Escuela de Chicago introdujeron un sesgo en el análisis global de la realidad chilena, de forma que por distintas circunstancias se ignoró la importancia de variables complementarias que han de ser tenidas en cuenta al definir las estrategias de desarrollo de las economías y especialmente si se tiene interés en alcanzar un cierto grado de éxito en los objetivos propuestos. Chile comenzó los 90 con una economía asentada sobre unas estructuras reformadas a la vez que recuperaba la democracia. Pero sin embargo, son muchos todavía los retos que Chile debe afrontar en el próximo milenio siendo necesario resaltar la superación de la pobreza, la vinculación de los sectores productivos locales, exportadores e internacionales, la disminución de la deuda externa, la diversificación de las exportaciones, la cualificación del mercado de trabajo, la seguridad ciudadana, etc.
El caso chileno viene a recordar la importancia que el análisis de los procesos históricos tiene para el devenir futuro ya que permite conocer los errores y los aciertos de las estrategias seguidas. De esta forma podríamos recordar las palabras de Jorge Luis Borges: "Solo una cosa no hay. Es el olvido".

\section{BIBLIOGRAFÍA BÁSICA}

AlLENDE, S. (1971): La vía chilena hacia el socialismo. Madrid: Editorial Fundamentos.

Arellano, R. (1993): "Las reformas estructurales de Chile, México y Colombia” en Monetaria, julio-septiembre. México: Centro de Estudios Monetarios Latinoamericanos. 257-305

CEPAL (1992): Equidad y transformación productiva: un enfoque integrado. Santiago de Chile: Naciones Unidas.

CortazA, R., Foxley, A. y Tokman, V. E. (1984): Legados del monetarismo: Argentina y Chile. Buenos Aires: Ediciones Solar.

EDWARDS, S. y Cox EDWARDS, A. (1992): Monetarismo y liberalización: El experimento chileno. México: Fondo de Cultura Económica.

HACHETTE, D. y LÜDERS, R. (1992): La privatización en Chile. Santiago de Chile: Centro Internacional para el Desarrollo Económico (CINDE).

LEHMANN, D. (1974): Agrarian reform and agrarian reformism. Great Britain: Faber and Faber Ltd.

MARTNER, G. (1975): "Los problemas de la producción bajo la Unidad Popular, 1970-1972”, Trimestre Económico. 167: 695-724

Serrano Spoerer, A. (1989): "Aplicación de medidas de reducción de la deuda en Chile", Boletín del Centro de Estudios Monetarios Latinoamericanos, 5: 229-234.

SunKel, O. (1992): "La consolidación de la democracia y del desarrollo en Chile". Revista de la Cepal. Núm. 47: 39-48.

VAldÉs, J. G. (1995): Pinochet's economists. Cambridge: Cambridge University Press. 


\section{RESUMEN}

En el presente artículo se recogen las principales reformas estructurales que han tenido lugar en Chile desde 1970 y que constituyen la base de la solidez actual de dicha economía latinoamericana. Se propone una división en períodos en la que se distingue la época del gobierno de la Unidad Popular, el gobierno de la Junta Militar y la transición a la democracia para evaluar los resultados económicos que se registraron a la luz de las distintas estrategias de desarrollo.

Las principales reformas que se dieron en el periodo 1970-1973 bajo la "vía chilena hacia el socialismo" fueron la creación del Área de Propiedad social, la profundización de la Reforma Agraria y la nacionalización de la Gran Minería

Durante el monetarismo ortodoxo (1974-1982) destacan como principales reformas la liberalización y desregulación de los mercados, la $1^{\mathrm{a}}$ ronda de privatizaciones, la apertura comercial, la liberalización financiera y las "siete modernizaciones", todas ellas respaldadas por la ortodoxia de la denominada Escuela de Chicago. Tras la profunda crisis de 1982 que afectó a todo el continente latinoamericano fue necesario replantear el modelo y se introdujeron distintas medidas de carácter neoliberal que consiguieron que fuera posible aprovechar los beneficios de las reformas realizadas con anterioridad.

La transición a la democracia constituye un reto para la sociedad chilena, en tanto que contando con las bases de una economía sólida deben incorporarse la visión social y política para que el crecimiento se convierta en desarrollo. En este sentido toma importancia la última estrategia de la CEPAL de "Transformación productiva con equidad".

Palabras clave: Reformas Estructurales - Chile - Política Económica de la Unidad Popular - Chicago Boys Transición a la democracia - Transformación productiva con equidad

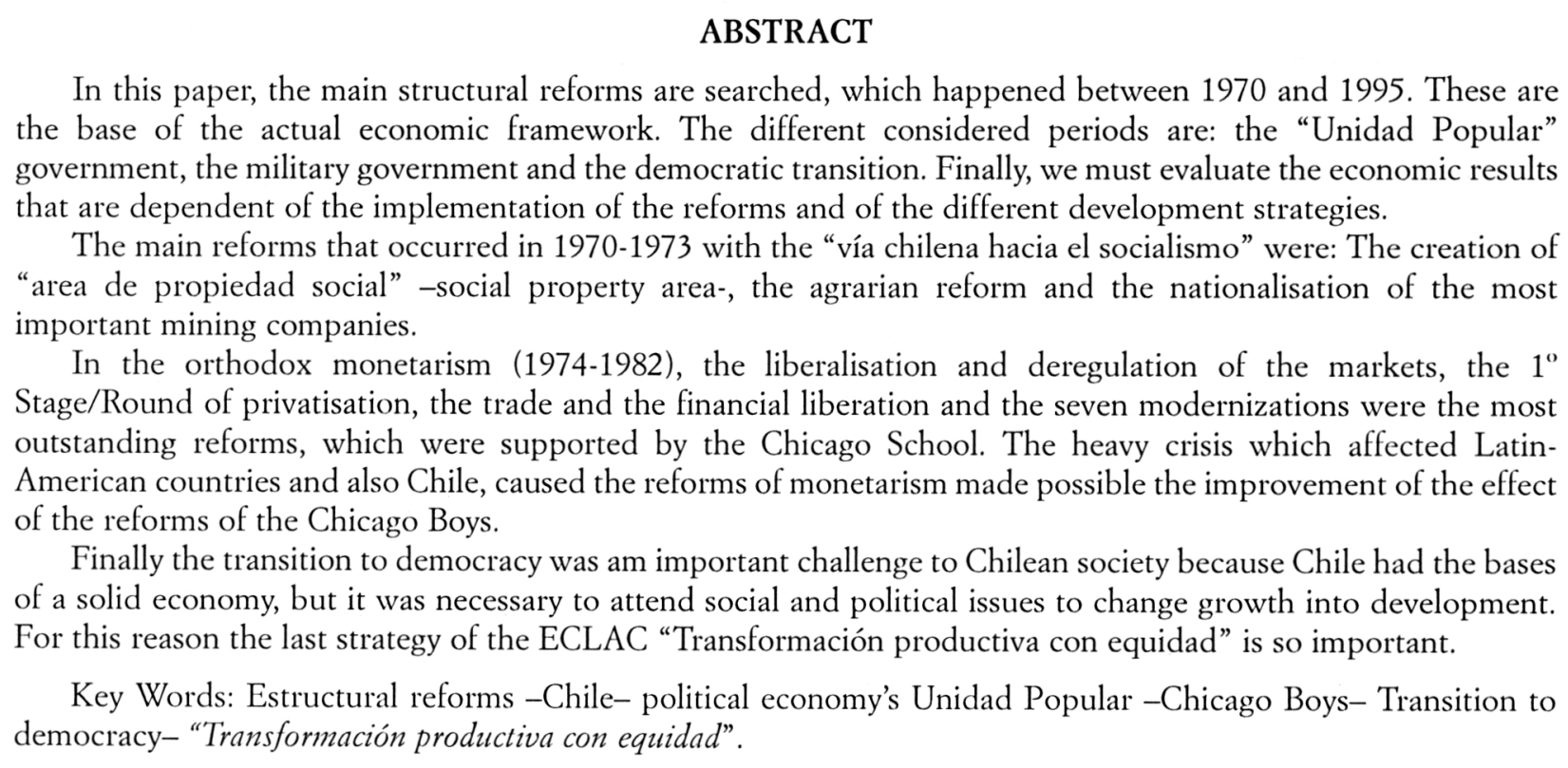

In this paper, the main structural reforms are searched, which happened between 1970 and 1995. These are the base of the actual economic framework. The different considered periods are: the "Unidad Popular" government, the military government and the democratic transition. Finally, we must evaluate the economic results that are dependent of the implementation of the reforms and of the different development strategies.

The main reforms that occurred in 1970-1973 with the "vía chilena hacia el socialismo" were: The creation of "area de propiedad social" -social property area-, the agrarian reform and the nationalisation of the most important mining companies.

In the orthodox monetarism (1974-1982), the liberalisation and deregulation of the markets, the $1^{\circ}$ Stage/Round of privatisation, the trade and the financial liberation and the seven modernizations were the most outstanding reforms, which were supported by the Chicago School. The heavy crisis which affected LatinAmerican countries and also Chile, caused the reforms of monetarism made possible the improvement of the effect of the reforms of the Chicago Boys.

Finally the transition to democracy was am important challenge to Chilean society because Chile had the bases of a solid economy, but it was necessary to attend social and political issues to change growth into development. For this reason the last strategy of the ECLAC "Transformación productiva con equidad" is so important.

Key Words: Estructural reforms -Chile- political economy's Unidad Popular -Chicago Boys- Transition to democracy- "Transformación productiva con equidad". 